\title{
Induction of Primary Male in Juvenile Red Spotted Grouper Epinephelus akaara by Immersion of 17a-Methyltestosterone
}

\author{
Chi-Hoon Lee ${ }^{1}$, Sang-Woo Hur ${ }^{2}$, Oh-Soo Na ${ }^{3}$, Hae-Ja Baek ${ }^{4}$, Choong-Hwan Noh ${ }^{5}$, \\ Sang-Hyun Han ${ }^{6}$ and ${ }^{\dagger}$ Young-Don Lee ${ }^{2}$ \\ ${ }^{I}$ CR Co., Ltd., Jeju 695-965, Korea \\ ${ }^{2}$ Marine Science Institute, Jeju National University, Jeju 695-965, Korea \\ ${ }^{3}$ Jeju Technopark, Jeju 699-121, Korea \\ ${ }^{4}$ Department of Marine Biology, Pukyong National University, Busan 608-7387, Korea \\ ${ }^{5}$ East Sea Research Institute, Korea Institute of Ocean Science and Technology, Uljin 767-813, Korea \\ ${ }^{6}$ Educational Science Research Institute, Jeju National University, Jeju 690-756, Korea
}

\begin{abstract}
We investigated the androgenic effects of $17 \alpha$ - methyltestosterone (MT) on gonadal sex reversal in juvenile red spotted grouper Epinephelus akaara. The fish were immersed in $17 \alpha-\mathrm{MT}$ at 1 and $5 \mathrm{mg} / \mathrm{L}$. Treatment method of $17 \alpha-\mathrm{MT}$ was once weekly for 4 and 8 weeks. Fish were sampled at 12 months after end of the treatment period in order to histological analysis. At the initiation of an experiment (70 day after hatching), juvenile red spotted grouper have the paired primordial gonads with somatic cells bellow kidney in the posterior portion of the body cavity. Formation of ovarian cavity indicates that the ovarian differentiation beginning at $70 \mathrm{DAH}$ in red spotted grouper. At 12 months after end of the treatment period, control group, 17 $\alpha$-MT $1 \mathrm{mg} / \mathrm{L}$ treatment group for 4 and 8 weeks, and 17 $\alpha$-MT $5 \mathrm{mg} / \mathrm{L}$ treatment group for 4 weeks were all female. However, sex-changed males without ovarian cavity were observed in the $17 \alpha-\mathrm{MT} 5 \mathrm{mg} / \mathrm{L}$ treatment group for 8 weeks. In grouper, we firstly reported that the red spotted grouper be able to induce the primary males by hormone treatment prior to gonadal sex differentiation.
\end{abstract}

Key words : Red spotted grouper, Epinephelus akaara, Gonadal sex differentiation, Sex change, Primary males

\section{INTRODUCTION}

The red spotted grouper, Epinephelus akaara is one of the most important grouper species for aquaculture in Korea, China, Japan and Southeast Asian countries. In particular, groupers are ideal candidate species for intensive aquaculture in Asia Pacific region because of high consumer demand, desirable taste, efficient feed conversion, and rapid growth (Kohno et al., 1993; Chen \& Tsai, 1994; Millamena, 2002). Despite its advantages as commercial importance culture species is still in infancy with adult management, natural spawning and seed production because most groupers require culture periods of several years until first maturation and spawning is achieved (Song et al., 2005). The problems of

\footnotetext{
Manuscript received 3 July 2014, Received in revised form 11 July 2014, Accepted 17 July 2014

$\dagger$ Corresponding Author : Young-Don Lee, Marine Science Institute, Jeju National University, Jeju 695-965, Korea. Tel. : +82-64-782-8922, E-mail : leemri@cheju.ac.kr

This is an Open Access article distributed under the terms of the Creative Commons Attribution Non-Commercial License (http:// creativecommons.org/licenses/by-nc/3.0) which permits unrestricted non-commercial use, distribution, and reproduction in any medium, provided the original work is properly cited.
} 
grouper aquaculture development has been hindered by the difficulty of mature male grouper security, which is due to the lack of a standardized method of sex change and the unavailability of mature male broodstock.

Most groupers including the red spotted grouper are protogynous hermaphrodites, first become sexually mature as females and later change sex to become males. Natural sex change in grouper species occurs between 3 and 11 years of age depending on the species (Tan \& Tan, 1974; Chauvet, 1988). The steroid hormones play important role of sex change in the grouper species (Li et al., 2006; Zhou \& Gui, 2010). Many study have been reported on different grouper species to develop standardized methods for sex reversal by treatment with androgens or aromatase inhibitors (Bhandari et al., 2005). But sex-changed male grouper had testis with ovarian cavity and sperm production is very low. Thus, in order to have a stable supply of sperm, it is necessary for male groupers without ovarian cavity using hormone treatment prior to ovarian cavity formation. In this study, we examined that the effect of $17 \alpha$-methyltestosterone (MT) to induce the primary male of juvenile red spotted grouper E. akaara.

\section{MATERIALS AND METHODS}

The experiments were carried out in Marine Science Institute, Jeju National University. At each experimental group, 200 fish were reared in $300 \mathrm{~L}$ circle tank with flowthrough sea water, under natural water temperature and photoperiod. At 70 days after hatching (Total length, 3.33 $0.38 \mathrm{~cm}$; Body weight, $0.47 \pm 0.14 \mathrm{~g}$ ), fish were immersed in $17 \alpha-\mathrm{MT}$ at 1 and $5 \mathrm{mg} / \mathrm{L}$. Treatment method of $17 \alpha-\mathrm{MT}$ was once weekly for 4 and 8 weeks. Fish were sampled at 12 months after end of the treatment period in order to histological analysis. The gonads were fixed in Bouin's solution, embedded in paraffin, cross-sectioned, and stained with haematoxylin and eosin using the standard methods for light microscopy.

\section{RESULTS AND DISCUSSION}

At the initiation of an experiment (70 day after hatching), juvenile red spotted grouper have the paired primordial gonads with somatic cells bellow kidney in the posterior portion of the body cavity. Each lobe of the primordial gonads began elongation to form an ovarian cavity (Fig. 1) In grouper species, gonad development during sexual differentiation is a little studied but similar patterns as early characteristic of female differentiation were reported (Murata et al., 2009; Liu \& Sadovy, 2009; Tsai et al., 2011; Sao et al., 2012). In E. malabaricus, the initial ovarian cavity was observed at 47 day after hatching by elongations of somatic cells in the gonads on the sides facing the gonad lateral walls, an early event of initial ovarian cavity formation (Murata et al., 2009). In E. coioides and E. bruneus, the initial ovarian phase was observed at 4 month after hatching and 60 day after hatching, respectively (Tsai et al., 2011; Sao et al., 2012). In this study, early morphological change to form the initial ovarian cavity in red

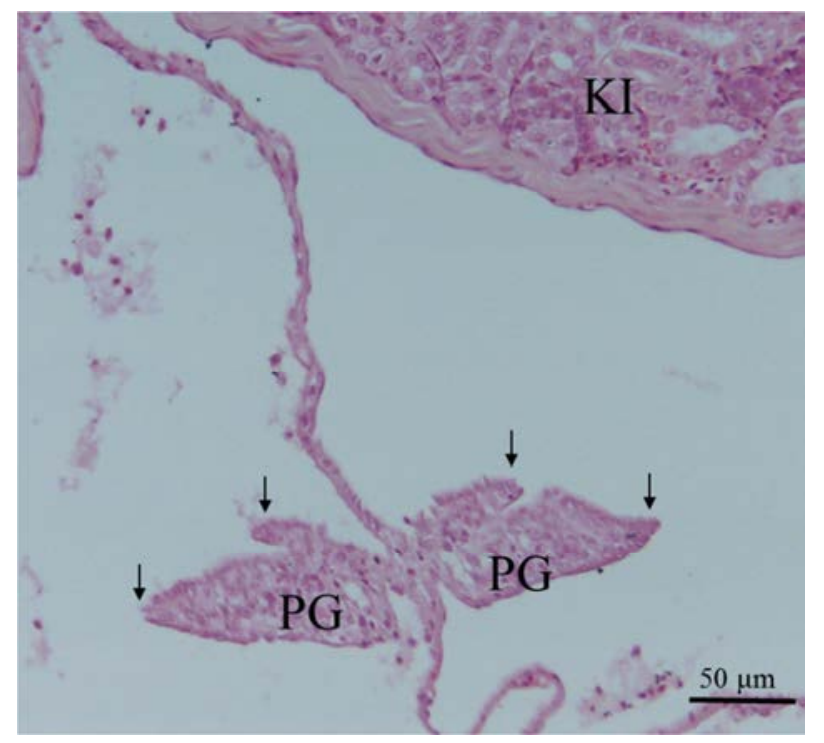

Fig. 1. Cross section gonad of juvenile red spotted grouper at 70 day after hatching. Two elongations of somatic tissue (arrow), indicating ovarian cavity formation, can be seen. KI, kidney; PG, primordial gonad. 
spotted grouper were observed by around 70 day after hatching.

Sex pattern of protogynous hermaphroditic fish can be divided into two types, mondary and diandry, according to the male development pathway (Reinboth, 1967). Monandric species follow a single male developmental pathway; all males in a population are secondary males derived exclusively from functional females via sex change. Diandric species follow two male developmental pathways, i.e., primary males develop from juveniles through sexual differentiation and secondary males develop via sex change. In Halichoeres poecilopterus, H. tenuispinis, and Ps. sieboldi were dianric type with primary and secondary male. Most grouper is mondary type with secondary male via sex change from functional female (Lee et al., 2006).

At 12 months after end of the treatment period, control group, $17 \alpha-\mathrm{MT} 1 \mathrm{mg} / \mathrm{L}$ treatment group for 4 and 8 weeks, and $17 \alpha$-MT $5 \mathrm{mg} / \mathrm{L}$ treatment group for 4 weeks were all female, which is contained oogonia and perinucleolus oocytes in ovary. However, sex-changed males were observed in the $17 \alpha-M T 5 \mathrm{mg} / \mathrm{L}$ treatment group for 8 weeks. The gonad of sex changing individuals was consisted of numerous testicular lobules and filled with sperm, but cannot observed the ovarian cavity (Fig. 2).

In many grouper species, successful induction of artificial sex change has been reported mostly in small sized females (Tukashima \& Kitajima, 1983: Chao \& Chow, 1990; Tsuchihashi et al., 2003). Androgen administration including 11 -ketotestosterone (11-KT) and the synthetic $17 \alpha$-methyltestosterone (MT) widely used for sex reversal induction in grouper, but various dose concentrations and methods of hormone administration (Chao \& Lim, 1991; Tsuchihashi et al., 2003; Lee et al., 2010). However, these methods of hormone administration have problem such as incomplete sex inversion and reverted back to being females during the next reproductive period (Marino et al., 2000; Sarter et al., 2006; Oh et al., 2013). Therefore, the most effective treatment time for artificial sex change induction by
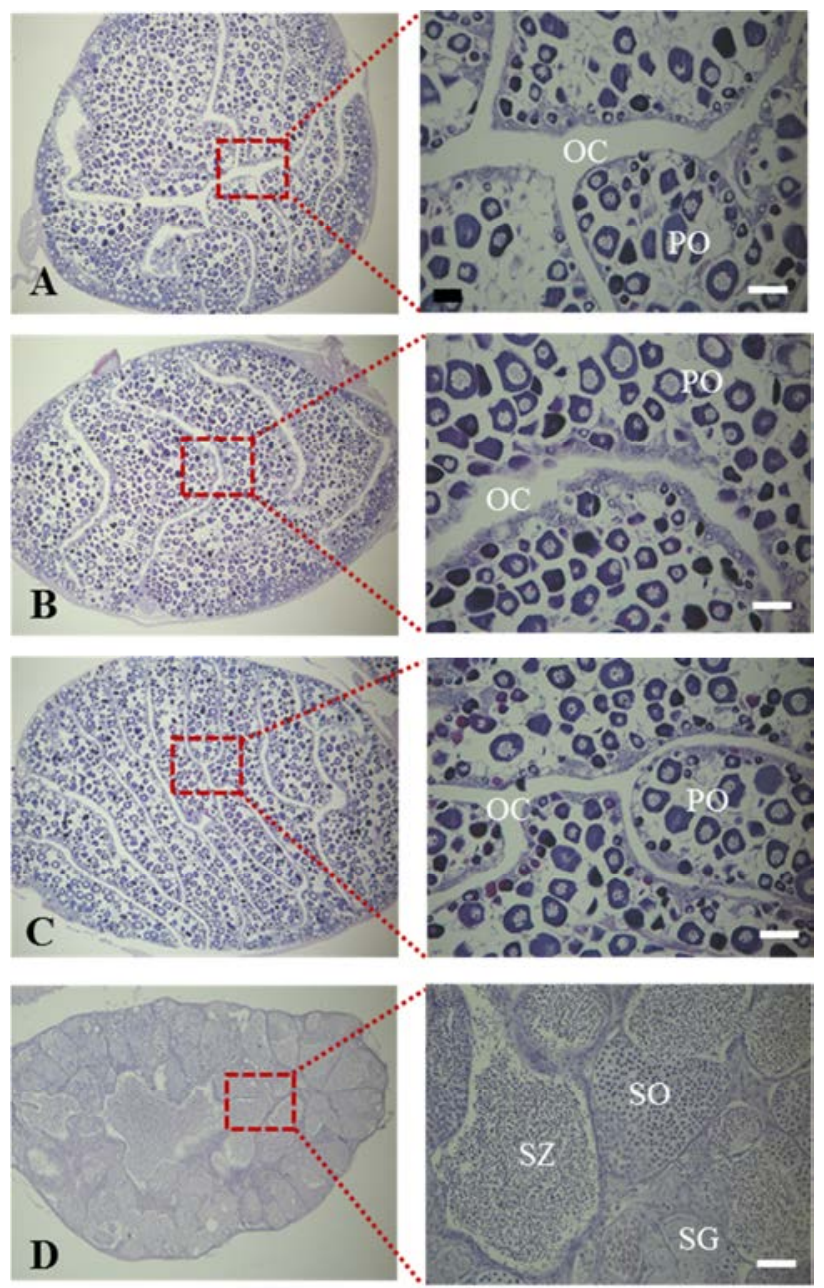

Fig. 2. Cross section gonad of juvenile red spotted grouper at 12 month after hatching. A, control group; $\mathrm{B}$, treatment group after immersion with $17 \alpha-\mathrm{MT} 1 \mathrm{mg} / \mathrm{L}$ for 4 and 8 weeks; C, treatment group after immersion with $17 \alpha-\mathrm{MT} 5 \mathrm{mg} / \mathrm{L}$ for 4 weeks; D, treatment group after immersion with $17 \alpha-$ MT $5 \mathrm{mg} / \mathrm{L}$ for 8 weeks. In A to $\mathrm{C}$ group, fish were all female with ovarian cavity and consisted of numerous ovarian lamellae with perinucleolus oocyte. In D group, fish were induced primary male without ovarian cavity and consisted of numerous testicular lobules with spermatogonia, spermatocyte and spermatozoa. OC, ovarian cavity; PO, perinucleolus oocytes; SG, spermatogonia; SO, spermatocyte; SZ, spermatozoa. Scale bars indicate $50 \mu \mathrm{m}$ (A to C) and $100 \mu \mathrm{m}(\mathrm{D})$. 
steroid hormone is during gonadal sex differentiation. In this study, sex-changed males without ovarian cavity were observed when juvenile red spotted grouper (70 DAH) were immersed in $17 \alpha-\mathrm{MT} 5 \mathrm{mg} / \mathrm{L}$ for 8 weeks. These results suggested that the red spotted grouper be able to induce the primary males by hormone treatment prior to gonadal sex differentiation.

\section{ACKNOWLEDGEMENTS}

Tish research was supported by Golden Seed Project, Ministry of Agriculture, Food and Rural Affairs (MAFRA), Ministry of Oceans and Fisheries (MOF), Rural Development Administration (RDA) and Korea Forest Service (KFS).

\section{REFERENCES}

Bhandari RK, Alam MA, Higa M, Soyano K, Nakamura M (2005) Evidence that estrogen regulates the sex change of honeycomb grouper (Epinephelus merra), a protogynous hermaphrodite fish. J Exp Zool 303A:497-503.

Chao TM, Chow M (1990) Effect of methyltestosterone on gonadal development of Epinephelus tauvina (FORSKAL). Singapore J Prim Ind 18:1-14.

Chao TM, Lim LC (1991) Recent development in the breeding of grouper (Epinephelus spp.) in Singapore. Singapore J Pri Ind 19:79-33.

Chauvet C (1988) Etude de la croissance du me'rou Epinephelus guaza des co`tes tunisiennes. Aquat Living Resour 1:277-288.

Chen HY, Tsai JC (1994) Optimal dietary protein level for the growth of juvenile grouper, Epinephelus malabaricus, fed semipurified diets. Aquaculture 119:265-271.

Kohno H, Diani S, Supriatna A (1993) Morphological development of larval and juvenile grouper, Epinephelus fuscoguttatus. Jpn J Ichthyol 40:307-316.

Lee CH, Hur SW, Song YB, Takano K, Takamura A, Lee
YD (2010) Effect of 11-ketotestosterone (11-KT) on gonadal sex reversal and spermatogenesis of honeycomb grouper Epinephelus merra. Dev Reprod 14:1-5.

Lee CH, Kim YS, Lee YD (2006) Sex characterization of wrasses inhabiting in the coastal waters of Jeju, Korea. Dev Reprod 10:79-84.

Li GL, Liu XC, Lin HR (2006) Effects of aromatizable and nonaromatizable androgens on the sex inversion of redspotted grouper (Epinephelus akaara). Fish Physiol Biochem 32:25-33.

Liu M, Sadovy Y (2009) Gonad development during sexual differentiation in hatchery-produced orange-spotted grouper (Epinphelus coioides) and humpback grouper (Cromileptes altivelis) (Pisces: Serranidae, Epinephelinae). Aquaculture 287:191-202.

Marino G, Azzurro E, Finoia MG, Messina MT, Massari A, Mandich A (2000) Recent advances in induced breeding of the dusky grouper Epinephelus marginatus (Lowe, 1834). Cahiers Options Mediterraneenes 47:215-225.

Millamena OM (2002) Replacement of fish meal by animal byproduct meals in a practical diet for grow-out culture of grouper Epinephelus coioides. Aquaculture 204:75-84.

Murata R, Karimata H, Alam MA, Nakamura M (2009) Gonadal sex differentiation in the malaba grouper, Epinephelus malabaricus. Aquaculture 293:286-289.

Oh SR, Kang HC, Lee CH, Hur SW, Lee YD (2013) Sex reversal and masculinization according to growth in longtooth grouper Epinephelus bruneus. Dev Reprod 17:79-85.

Reinboth R (1967) Biandric teleost species. Gen Comp Endocrinol 9:486.

Sao PN, Hur SW, Lee CH, Lee YD (2012) Gonadal sex differentiation of hatchery-reared longtooth grouper (Epinephelus bruneus) Dev Reprod 16:185-193.

Sarter K, Papadaki M, Zanuy S, Mylonas CC (2006) Permanent sex inversion in 1-year-old juveniles of the 
protogynous dusky grouper (Epinephelus marginatus)

using controlled-release $17 \alpha$-methyltestosterone implants. Aquaculture 256:443-456.

Song YB, Oh SR, Seo JP, Ji BG, Lim BS, Lee YD (2005) Larval development and rearing of longtooth grouper Epinephelus bruneus in Jeju Island, Korea. Journal of the World Aquaculture Society 36:209-216.

Tan SM, Tan KS (1974) Biology of the tropical grouper. Epinephelus tauvina (Forskal) I. A preliminary study on hermaphroditism in E. tauvina. Sing J Prim Ind 2:123-133.

Tsai YJ, Lee MF, Chen CY, Chang CF (2011) Development of gonadal tissue and aromatase function in the protogynous orange-spotted grouper Epinephelus coioides. Zool Stud 50:693-704.

Tsuchihashi Y, Tanaka H, Kuromiya Y, Kashiwagi M, Yoshioka M (2003) Control of induction of sex reversal in the sevenband grouper, Epinephelus septemfasciatus. Suisan Zoshoku 51(2):189-196.

Tukashima Y, Kitajima C (1983) Acceleration of sex reversal from immature female into functional males through oral administration of methyltestosterone in sevenband grouper, Epinephelus septemfasciatus (Thunberg). Bull Nagasaki Pre Ins Fis 9:55-57.

Zhou L, Gui JF (2010) Molecular mechanisms underlying sex change in hermaphroditic groupers. Fish Physiol Biochem 36:181-193. 